\title{
Surface Characteristics of Nanosized Bentonite Suspensions as a Modifying Component of Cement Composites
}

\author{
Abdullaev A.M. \\ Department of Physical and Mathematical Studies \\ Complex Research Institute named after Kh. I. Ibragimov, RAS \\ Grozny, Russia \\ han-100@mail.ru
}

\author{
Alikhadzhiev S.Kh. \\ Chechen State University \\ Physics and ICT Faculty \\ Grozny, Russia \\ Said366502@mail.ru
}

Dzhambulatov R.S.

Department of Physical and Mathematical Studies

Complex Research Institute named after Kh. I. Ibragimov, RAS

Chechen State Pedagogical University

Faculty of Natural Sciences

Grozny, Russia

\author{
Dadashev RKh. \\ Chechen State University \\ Physics and ICT Faculty \\ Grozny, Russia \\ asldzam@mail.ru
}

\author{
Abdullaev M.A-V. \\ Department of Materials Science \\ Complex Research Institute named after Kh. I. Ibragimov, \\ RAS Grozny, Russia \\ mgdaa@mail.ru \\ asldzam@mail.ru
}

Israilov M-A.M.

Chechen State University

Agrotechnological Institute

Grozny, Russia

aminisrailov@yandex.ru

\begin{abstract}
The paper presents the measured data on interfacial tension of bentonite suspensions and strength of a cement stone in water solutions of Frem Giper S-TB superplasticizer. The interfacial tension of water-surfactant-bentonite suspension is experimentally measured at various concentrations of a bentonite solid phase. The dependence of interfacial tension on the concentration of a solid phase is quite complex. In particular, the minimum is observed on interfacial tension isotherms at $3 \mathrm{wt} . \%$ of bentonite. Isoplastic cement mixes are obtained from the above suspensions. The cement stone samples are made of these mixes. The strength test of these samples showed a considerable increase of the compression strength. At the same time, $3 \mathrm{wt} . \%$ of bentonite demonstrated the maximum increase in strength.
\end{abstract}

Keywords-superplasticizing agent, surfactant, interfacial tension, nanosuspension, bentonite, dispersion, nanostructure, strength.

\section{INTRODUCTION}

In recent years, there is an ever-increasing interest to the study of the influence of various complex additives on the density and uniformity of concrete structure. One of efficient complex additives may include natural and activated bentonites paired with well-known superplasticizing agents, which are widely used in the production of construction concrete.
Various plasticizing additives, which reduce the interfacial tension of water and cement thus leading to their dispersion in a concrete mix, are used to achieve the uniform structure and optimum density of concrete [1, 2]. However, both from economic and environmental perspective it seems relevant to study the possibility of using cheap natural materials, namely bentonite, as nanostructured additives for concrete $[3,4]$.

Since the nanostructured additives represent systems with highly-developed surface, the interphase phenomena within the formation of their properties and interaction with a cement component play a key role. It is known that the dispersion in water suspensions of bentonites, being a hydrophilic system, is spontaneous.

The spontaneous dispersion implies the tendency of a disperse phase towards uniform distribution along the system volume (similar to the distribution of dissolved substance in true solutions), which leads to the formation of nanoparticles during spontaneous dispersion. The size of these particles may vary from several tens to several hundred nanometers in width and length, and from 1 to 1.5 nanometers in thickness $[5,6]$. They can also participate in thermal motion, accumulate on phase boundaries, and influence the interfacial tension of bentonite suspensions. The joint use of partially soluble surfactants in liquid mediums shall reduce the interfacial tension according to Antonov's rule [9]. Nanoparticles define 
the interaction between a suspension and a cement basis in a concrete mix, being a weak stress raiser causing consolidation and hardening of the material [7]. It is noted in works [8,9] that the decrease of the interfacial tension on interphase boundaries increases the activity of a dispersion system, smoothens the surface and consolidates its structure.

The purpose of the given research is to study the role of interfacial tension of bentonite suspensions separately and in conjunction with Frem Giper S-TB superplasticizer in the formation of a cement stone structure. Besides, it is scientifically crucial to study the dependence of surface properties of the dispersion system on concentration since the concentration factor is key in defining the main properties of dispersion systems.

\section{METHODS AND MATERIALS}

The following materials were used in experiments: Frem Giper S-TB superplasticizer produced in the Republic of Belarus; natural bentonite - in the Chechen Republic; M500 portland cement of Chiri-Yurtovsky cement plant of the Chechen Republic; tap water.

To measure the interfacial tension, the studied samples were prepared as follows: the amount of water and bentonite powder was measured on electronic scales. The Frem Giper S-TB was added with a micropipette (DV 100) and carefully mixed in a magnetic mixer (PE-6110) within 1 min. Bentonite suspensions in water were prepared in a similar manner. The laser analyzer of particles (Horiba LB 550) was used to study the size of bentonite particles and their quantitative distribution.

The suspension for analyses were prepared as follows: 120 $\mathrm{g}$ of water was weighed and the amount of bentonite was defined against the concentration of a component, and carefully mixed on a magnetic mixer (PE-6110) within $1 \mathrm{~min}$. The received suspension was analyzed in the ultrasonic unit (IL1006/2) within $10 \mathrm{sec}$.

The interfacial tension was measured via the hanging-drop method on a DSA100 tensiometer by Kruss Germany [10, 11, 13]. The measurement error of interfacial tension made less than $1 \%$. The cement paste of normal density was made on the basis of received water - six batches per each set of samples. At the same time, the bentonite content in water increased at the interval of $0.2 \mathrm{wt} . \%$ of cement. The composition of the cement paste and water for its preparation was selected for each component separately, and for their complex use - by analogy. The normal density of the cement paste was defined in accordance with GOST 310.3-76 "Cements. Methods of determination of normal density and setting time". The density of a cement stone was defined by hydrostatic weighing according to GOST 12730.1-2002 "Cements. Methods of determination of density".

The samples for a cement stone were made in standard metal forms with the cube edge of $20 \mathrm{~mm}$. Then, in 20 hours, the samples were taken from molds and kept in water at $293 \mathrm{~K}$ within 28 days prior to the strength test. The compression strength of a cement stone was defined via mechanical test of samples in FS150AT. The morphology of a cement stone was studied via SEM using Quanta 3D 200i (USA).

\section{RESULTS}

It is known that natural bentonites contain solid phase particles with the size of 100-1000 nanometers, and the nanostructured additives require about 10-100 nanometers. Therefore, for the purpose of dispersion, the studied samples of water suspensions of bentonite were exposed to ultrasonic influence during 10-15 sec. (frequency - $19.5 \mathrm{kHz}$, amplitude of variable sound pressure - 6 atm, amplitude of particle fluctuation - 2.42 microns, amplitude of particle acceleration $3.6 \times 104 \mathrm{~m} / \mathrm{c}^{2}$ ). The study showed that the ultrasonic exposure increases the stability of bentonite suspension and the stability of coagulative structures by 1.2-1.5 times, i.e. peptization of suspension characterizing the influence of ultrasound on structural-mechanical indicators of bentonite. The ultrasound dispersing force was checked via particle size analyzer HORIBA LB-550, which resulted in diagrams of particle distribution by size in bentonite suspension before and after ultrasonic exposure (Fig. 1,2).

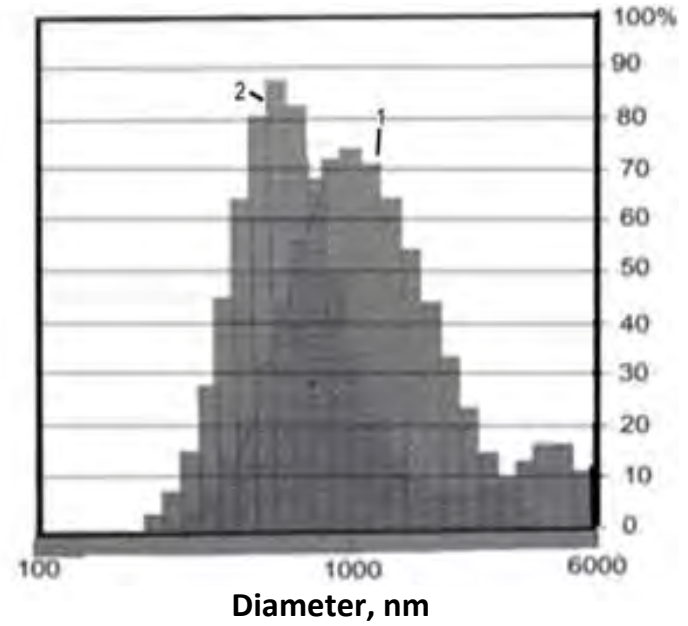

Fig. 1. Distribution of solid particles by size in bentonite suspension at $1 \%$ of the solid phase: 1 - prior to ultrasound, 2 - after ultrasound (10 sec.)

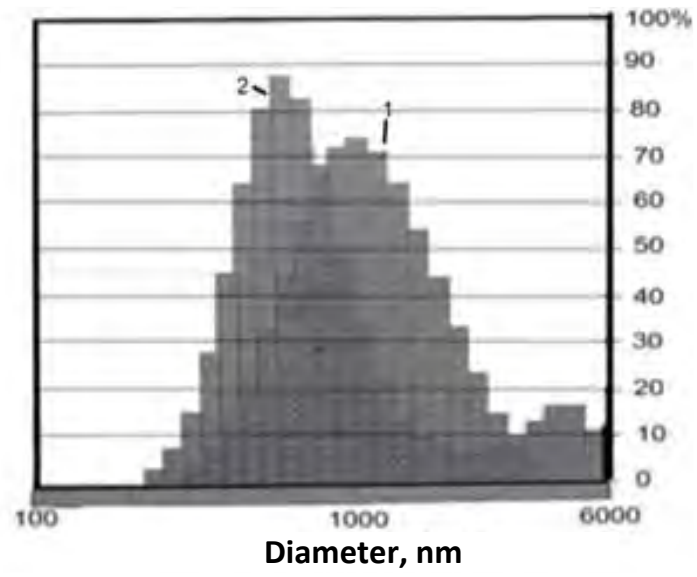

Fig. 2. Distribution of solid particles by size in bentonite suspension at $5 \%$ of the solid phase 5\%: 1 - prior to ultrasound, 2 - after ultrasound (10 sec.)

The obtained results show that the size of nanoparticles of suspensions subjected to ultrasonic dispersion ranges from 100 
to 1000 nanometers. Thus, the average size of nanoparticles for suspension subjected to ultrasonic influence makes 180-250 nanometers (Fig. 1-2)

The interfacial tension of bentonites suspension samples was measured separately and in a complex with Frem Giper STB at $293 \mathrm{~K}$. The results are shown in Fig. 3.

The study indicated the presence of extremum (isotherm 2) on isotherms of interfacial tension at $3 \mathrm{wt} . \%$. Monotonous decrease of interfacial tension to $3 \mathrm{wt} . \%$ of a solid phase allows making an assumption on the maximum accumulation of colloidal bentonite particles in the interphase layer - left part of isotherm 2

The isotherm 3 shows that at a complex use of Frem Giper S-TB with bentonite powder the interfacial tension decreases more intensively with the increase in the concentration of superplasticizer and bentonite than in case with the separate use of Frem Giper S-TB in water (isotherm 1) and reaches the minimum at $2 \mathrm{wt} . \%$ of bentonite and surfactant in water.

The interfacial tension decreases to $12 \mathrm{mN} / \mathrm{m}$ at initial concentration of a solid phase of up to $2 \%$ in bentonite suspension, which confirms the efficiency of fine-grained bentonite as a component able to impact the processes within the interphase layer.

The strength properties of a cement stone were studied to understand the influence of nanosized bentonite additives and a bentonite with surfactant on physicomechanical properties and superficial structure of a cement stone. Isoplastic cement mixes were prepared using the obtained solutions. Then, the cement stone cubic samples (20x20x20 mm in size) were made, which were consolidated in water within 28 days.

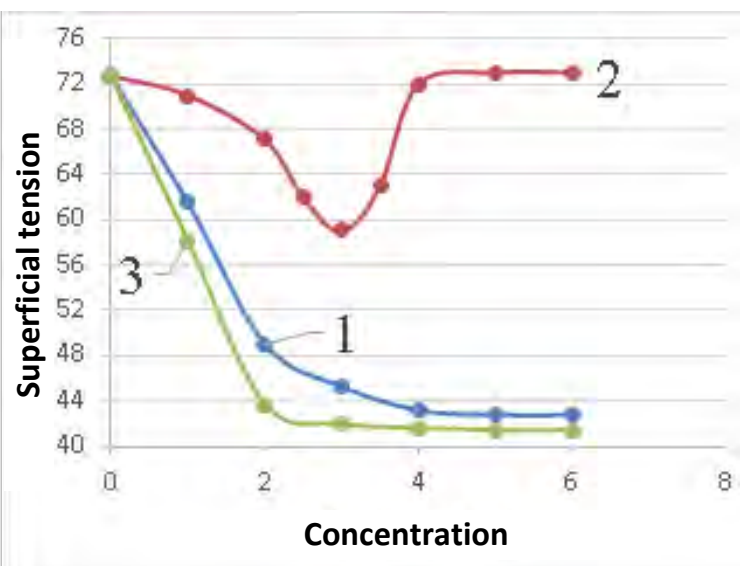

Fig. 3. . Isotherms of interfacial tension: 1 - Frem Giper S-TB in water; $2-$ bentonite suspension in water; 3 - bentonite suspension in Frem Giper S-TB in water

Table 1 shows the analysis of normal density of a cement paste according to GOST 310.3-76, density according to GOST 12730.1-2002 "Methods of determination of density", water interfacial tensions in the presence of additives, as well as physicomechanical characteristics of sample cement stone cubes of $20 * 20 * 20 \mathrm{~mm}$

TABle I. Properties Of The Cement Stone Received With The Use Of Nanostructured Components And Superplasticizer

\begin{tabular}{|c|c|c|c|c|c|c|c|c|}
\hline $\begin{array}{c}\text { Cement } \\
\text { consumption, } g\end{array}$ & $\begin{array}{c}\text { Frem } \\
\text { Giper S- } \\
\text { TB, wt. } \\
\% \text { of } \\
\text { cement }\end{array}$ & $\begin{array}{c}\text { Frem } \\
\text { Giper S- } \\
\text { TB, wt. \% } \\
\text { of water }\end{array}$ & $\begin{array}{c}\text { Bentonite } \\
\text { powder } \\
\text { content, \% } \\
\text { wt. of cement }\end{array}$ & $\begin{array}{c}\text { Bentonite } \\
\text { powder content, } \\
\text { wt. } \% \text { of water }\end{array}$ & $\begin{array}{c}\text { Interfacial } \\
\text { tension, } \\
\mathrm{mN} / \mathrm{m}\end{array}$ & $\begin{array}{c}\text { Normal } \\
\text { consistency } \\
\text { (NC), \% }\end{array}$ & $\begin{array}{l}\text { Cement } \\
\text { stone } \\
\text { density, } \\
\text { g/cm } \\
\text { 3 }\end{array}$ & Strength, MPa \\
\hline 500 & & & & & 72.7 & 23.25 & 2.18 & 112.5 \\
\hline 500 & & & 0.2 & 0.86 & 71.0 & 23.25 & 2.204 & 117.4 \\
\hline 500 & & & 0.4 & 1.72 & 67.1 & 23.25 & 2.2 & 121.9 \\
\hline 500 & & & 0.6 & 2.58 & 62 & 24.2 & 2.16 & 120.5 \\
\hline 500 & & & 0.8 & 3.43 & 60.1 & 25.3 & 2.16 & 114.3 \\
\hline 500 & & & 1.0 & 3.95 & 72 & 26.8 & 2.11 & 114.8 \\
\hline 500 & 0.2 & 0.94 & & & 63.1 & 21.2 & 2.28 & 122.4 \\
\hline 500 & 0.4 & 2.04 & & & 49.1 & 19.6 & 2.32 & 127.6 \\
\hline 500 & 0.6 & 3.26 & & & 45.3 & 18.4 & 2.32 & 132.9 \\
\hline 500 & 0.8 & 4.38 & & & 42.79 & 18.25 & 2.32 & 131.3 \\
\hline 500 & 1.0 & 5.5 & & & 42.75 & 18.25 & 2.32 & 130.2 \\
\hline 500 & 0.2 & 1.14 & 0.2 & 1.14 & 56.7 & 18.5 & 2.35 & 133.6 \\
\hline 500 & 0.4 & 2.28 & 0.4 & 2.28 & 43.1 & 17.6 & 2.35 & 137.2 \\
\hline 500 & 0.6 & 3.38 & 0.6 & 3.38 & 41.6 & 17.75 & 2.35 & 136.8 \\
\hline 500 & 0.8 & 4.49 & 0.8 & 4.49 & 41.4 & 17.8 & 2.35 & 132.1 \\
\hline 500 & 1.0 & 5.63 & 1.0 & 5.63 & 41.4 & 17.8 & 2.34 & 128.2 \\
\hline
\end{tabular}

The introduction of powdery natural bentonite (Table 1) leads to considerable difference in the compression strength of the studied samples from the control ones (composition 1). At the same time, the maximum density and strength of the studied concrete samples is reached in the range of bentonite concentration of $2.28-3.38 \%$ in mixing water. 
Fig. 4 shows the concrete strength depending on bentonite concentration as a part of a complex additive (Table 1) and the interfacial tension of bentonite suspensions. As is seen from this figure, the isotherm of the interfacial tension dependence (isotherm 2) is characterized by the minimum in the field of 3 wt. \% concentration of bentonite. The isotherm 1 shows experimental data on strength dependence of concrete samples on the bentonite solid phase concentration in water suspension used as a combined additive for concrete. The obtained data show the maximum strength of the studied concrete samples in the concentration of 3-4 wt. \% of a bentonite solid phase as part of the combined additive.

The comparison of isotherms of interfacial tension of bentonite suspension and the strength of concrete made with the addition of such amount of bentonite, where the minimum is observed in the suspension (Fig. 4), shows the correlation between the minimum and the maximum of the studied parameters. The obtained data indicate the correlation between the water interfacial tension in the presence of complex additive (bentonite - Frem Giper S-TB) and the strength of the cement stone made with this additive.

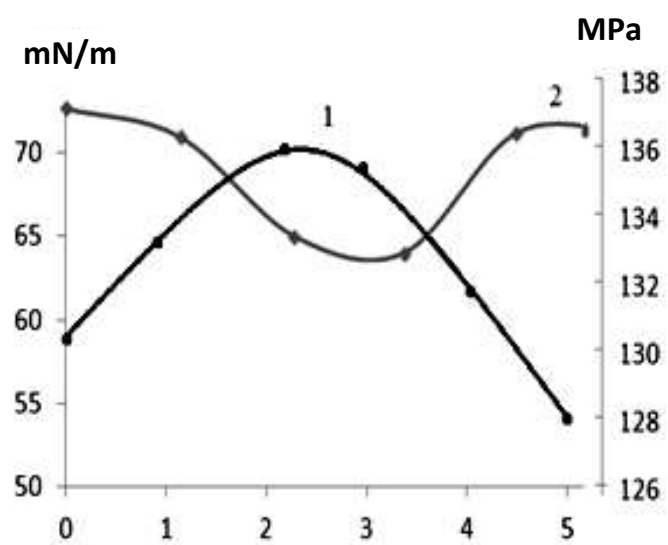

Fig. 4. Dependence of interfacial tension and concrete strength on bentonite solid phase content used as a combined additive in concrete. 1 - dependence of concrete strength on bentonite content as part of complex additive; 2 dependence of interfacial tension on bentonite content in suspension

At the same time, the normal density of a cement paste with the introduction of bentonite powder slightly changes, but differs from the control sample by $24 \%$ at the complex use of bentonite with Frem Giper S-TB. The strength of samples made with bentonite powder as an additive exceeds the control values by $8.4 \%$.

At the complex use of a superplasticizer and a bentonite clay powder the strength of a cement stone increases by $22 \%$ in comparison with the control sample. This may be explained by the fact that the interfacial tension at the complex use of superplasticizer and bentonite clay decreases more efficiently than when each of these additives are used separately, which leads to the compliance with stability conditions of boundary films of a liquid phase according to $[8,9]$.

$$
\frac{\partial \Pi}{\partial h}<-\frac{m \sigma}{(r+h)^{2}}
$$

where $\mathrm{m}=2$ for convex spherical particles; $\mathrm{r}$-particle radius; $\mathrm{h}$ - liquid film thickness; $\partial \Pi$ - wedging pressure.

Consequently, with the decrease of the interfacial tension from $72.7 \mathrm{mN} / \mathrm{m}$ to $42 \mathrm{mN} / \mathrm{m}$ at the complex use of Frem Giper $\mathrm{S}-\mathrm{TB}$ and bentonite powder nanoparticles it is possible to reduce the film thickness on convex surfaces of particles thus ensuring the stability of such films, which allows fixing particles of a dispersion phase in dispersive media at a short distance (h). Further increase in the concentration of both components negatively influences the strength properties of a cement stone, which, according to our assumptions, is caused by excessive dispersion of cement during mixing with water with low interfacial tension.

In order to justify the reliability of obtained results and establish their correlation with the cement stone microstructure the surfaces of a cement stone were studied before and after the introduction of additives via scanning electron microscope (Fig. $5-7)$

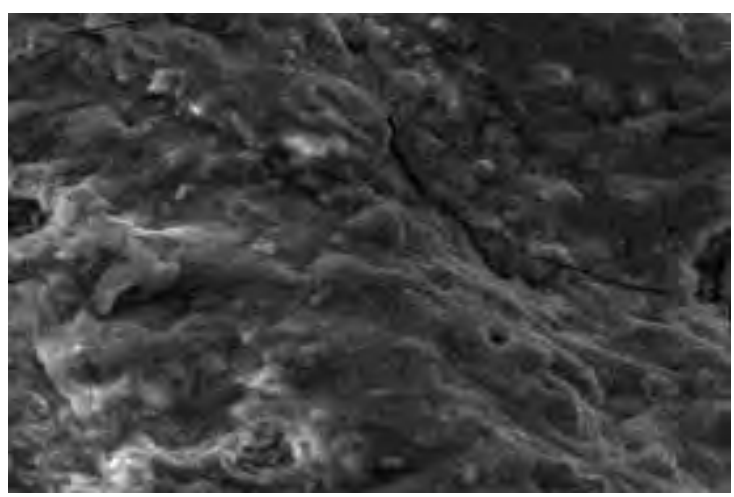

Fig. 5. Cement stone (without additives)

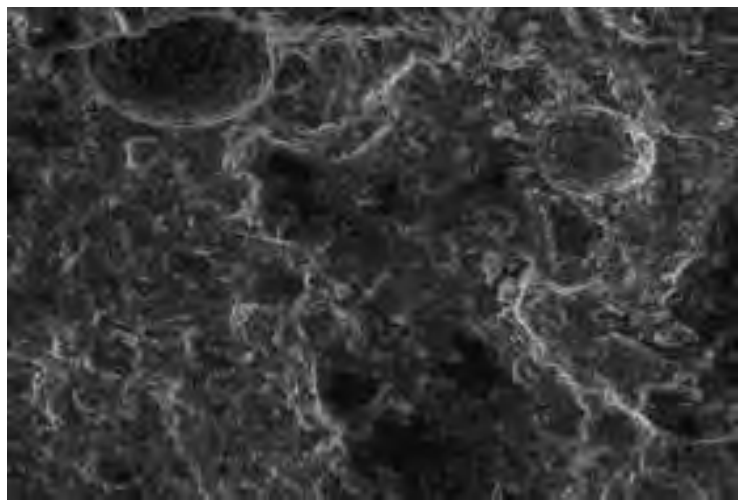

Fig. 6. Cement stone with nanoparticles of bentonite powder 


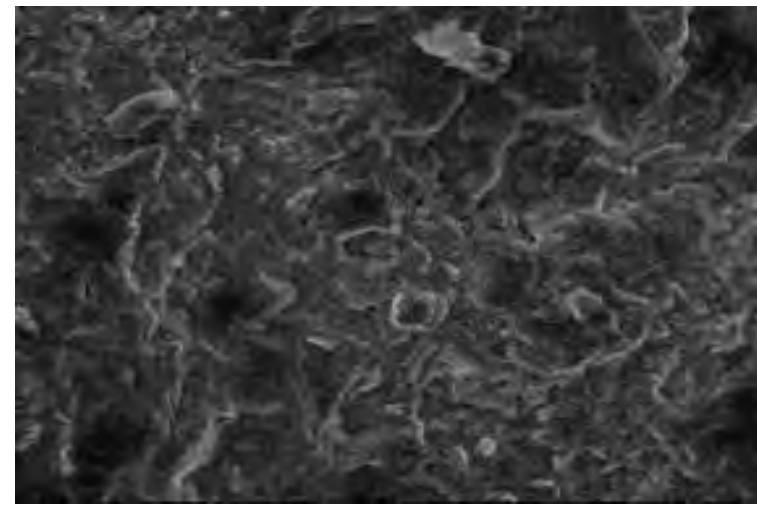

Fig. 7. Cement stone with the addition of Frem Giper S-TB and nanoparticles of bentonite powder

The analysis of obtained data shows that in comparison with a control sample, the surface of a cement stone with bentonite powder nanoparticles has minor defects and the number of cracks is limited. Besides, there are pores in places of moisture evaporation that coincides well with obtained results on the strength of a cement stone. However, the cement stone samples prepared using a complex additive differ from other samples by their denser structure. Cement samples with complex additives based on a superplasticizer and a bentonite clay have smooth surface and uniform structure. The obtained images also lack microcracks and pores from water evaporation, which is coherent with the results of compression strength tests.

\section{CONCLUSIONS}

The decrease of interfacial tension as a result of complex use of Frem Giper S-TB and bentonite powder leads to thinner film of water on convex surfaces of cement particles thus maintaining its stability, which allows cement particles to be settled at the shortest possible distances. This ensures consolidation of a cement stone structure, formation of stronger links between narrowed cement particles during hydration. The fact that the minimum of the water interfacial tension with the use of additives is reached at the minimum concentration of these additives can be beneficial since less additives will be consumed in concrete production. The use of natural bentonite [15] to increase the efficiency of chemical products representing surfactants reveals new opportunities to produce cheaper and eco-friendly natural materials.

\section{References}

[1] A.M. Abdullaev, S.-A.Yu. Murtazayev, Improvement of specific surface of cements via the dispersing action of highly efficient surfactants, Bulletin of BGTU named after V.G. Shukhov, No. 1, pp. 40-45, 2016.

[2] P.A. Rebinder, Surface phenomena in dispersion systems. Physicochemical mechanics. Moscow: Science, 1979, pp. 246-250.

[3] A.S. Korolev, E.Sh. Khakimova, Fine-grained concrete with synthetic zeolite nanoadditives, Concrete and reinforced concrete, No. 6, pp. 13-15, 2008.

[4] A.N. Ponomarev, Perspective constructional materials and technologies created using nanodispersed fulleroid systems, Questions of materials science, No. 2, pp. 65-69, 2001.

[5] S.A. Kononenko, Technological fundamentals for modification of bentonite of Tarasovsky Field for forming mixes. Novocherkassk. extended abstract of Cand. Sci. Dissertation, 2009, pp. 120.

[6] V.V. Ponomarev, Study of structure and adsorptive properties of natural and modified bentonites, News of higher educational institutions. North Caucasus region. Technical science, No. 3, pp. 94-97, 2008.

[7] V.E. Panin, E.E. Deryugin, S.N. Kulkov, Mesomechanics of materials hardening with nanodispersed inclusions, Applied mechanics and technical physics, No. 4, pp. 127-142, 2010.

[8] A.N. Smirnov, Definition of interfacial tension isotherms of grain boundaries on the basis of adsorptive measurements. Surface. X-ray, synchrotron and neutron studies, No. 5, pp. 93-96, 2005.

[9] E.V. Mikheyeva, N.P. Pikula, S.N. Karbainova, Superficial phenomena and dispersion systems. Colloidal chemistry. Tomsk: TPU publishing house, 2008, pp. 16.

[10] R.Kh. Dadashev, V.H. Mezhidov, R.S. Dzhambulatov, D.Z. Elimkhanov, Features of interfacial tension isotherms of water suspensions of bentonites, RAS News. Physics, No. 4, pp. 433-435, 2014.

[11] R.Kh. Dadashev, R.S. Dzhambulatov, V.H. Mezhidov, D.Z. Elimkhanov, Features of interfacial tension isotherms of water suspensions of natural bentonites, Bulletin of the Academy of Sciences of the Chechen Republic, No. 3, pp. 5-10, 2013.

[12] Official website of KRUSS Company: http://www.kruss.de.

[13] R.Kh. Dadashev, R.S. Dzhambulatov, D.Z. Elimkhanov, et al., Installation to study superficial properties of a phase boundary (DSA100), Bulletin of the Academy of Sciences of the Chechen Republic, No. 1, pp. 13-17, 2011.

[14] V.I. Osipov, Physical and chemical theory of effective tension in soil, PEDOLOGY, No. 2, pp. 3-34, 2013. 